\title{
New drugs for Alzheimer's disease and other
}

\section{dementias $^{\dagger}$}

ROGER BULLOCK

\section{Background Alzheimer's disease management involves symptomatic drug treatments passed by the National Institute for Clinical Excellence. Disease modification is now the goal.}

Aims To review current and developmental drugs for Alzheimer's disease, their usage, and the clinical context of known facts and proposed specific models.

\section{Method Abrief evidence-based} review was made, using literature where available, or evidence from consensus groups where it was absent.

Results There is good evidence to support the use of cholinesterase inhibitors, and perhaps vitamin E. Oestrogen and anti-inflammatory agents show possibility, but there is not enough evidence to support routine use.

Conclusions Symptomatic treatments exist for Alzheimer's disease.

Observational studies and increasing knowledge of brain biology are leading towards further treatment options. Old age psychiatrists have valuable treatments they now have to learn to use.

Declaration of interest R.B. has worked on clinical trials in dementia for all the major pharmaceutical companies.

†See editorial, pp. 97-98, this issue.
The cholinergic hypothesis of Alzheimer's disease (Davies \& Maloney, 1976) has led to the development of a number of strategies to enhance the failing cholinergic neurons and thus the neurotransmitter, acetylcholine. The most consistent therapeutic effect has been seen using inhibitors of the enzyme acetylcholinesterase, which cleaves the transmitter in the cholinergic synapse. Three such compounds have now been licensed for the treatment of $\mathrm{Alz}$ heimer's disease: donepezil, rivastigmine and galantamine. These have increased awareness of Alzheimer's disease, but unfortunately cost pressures have hindered their development in the UK, even though experienced users of donepezil and rivastigmine have found consistent results (Cameron et al, 2000; Evans et al, 2000; Matthews et al, 2000). The acetylcholinesterase inhibitors (AChEIs) were considered to be a stepping-stone to better diseasemodifying compounds (Bullock, 1998). Although they undoubtedly are, no other class of drug has yet reached the clinic, and AChEIs will remain the main treatment option for some time. A variety of protocols for treatment (Harvey, 1999) have been superseded in the UK by the National Institute for Clinical Excellence (2001) guidelines on the use of these three drugs.

\section{PRACTICAL DILEMMAS IN THE USE OF ACETYLCHOLINESTERASE INHIBITORS}

The AChEI class of drugs all affect the measured domains of dementia in much the same way. The consistency of effect is evident from Fig. 1, which shows the cognition scores averaged from the pivotal trials of the three licensed compounds. This is a symptomatic response lasting approximately 8 months, followed by a decline that remains significantly above that of the placebo group for longer periods. This supports the preclinical cholinergic hypotheses (Davies \& Maloney, 1976). Exciting as this is, it is only symptomatic treatment at the end of a complex disease process analogous to the use of levodopa in Parkinson's disease. The AChEI class continues to present practical and scientific challenges that clinicians need to have resolved; meanwhile, different treatments continue in development.

\section{Who?}

In all trials of AChEIs, a 'response', as measured by the scales used, was found in an average of $40 \%$ of the patients studied (Corey-Bloom et al, 1998; Rogers et al, 1998; Raskind et al, 2000). This compares favourably with most drugs for chronic illness, and all AChEIs have low 'numbers needed to treat' (NNTs) (Livingston \& Katona, 2000). Using the scores from published data, donepezil has an NNT of 4 , rivastigmine 7 and galantamine 3 . The high placebo response is often questioned, but this is common in mental health studies, where it masks a large non-drug treatment effect. Responders and nonresponders are identified - but our criteria may be too harsh and the nature of a 'response' needs more research and definition. Currently no hard predictor of response or non-response has been identified (Schneider \& Farlow, 1995). The APOE4 allele was once suggested as a marker of poor response, but subsequent studies suggested no correlation.

In the absence of valid biological markers for Alzheimer's disease, measuring the effect intervention may have on the disease itself requires all patients to be treated for a reasonable length of time - perhaps up to 6 months. In reality, this depends on economics; so UK prescribers tend to work in subsets of mild to moderate dementia, excluding institutional patients with more advanced disease, and only prescribing to community-based patients who can have their medication supervised - as now ratified in the NICE guidelines.

\section{How?}

Various models of prescribing exist, all involving titration of the dose to minimise side-effects - particularly gastrointestinal ones. Donepezil has the advantage of having only two dose steps, while rivastigmine and galantamine offer a wider range, making tailoring to individual patients perhaps more precise. Whichever 


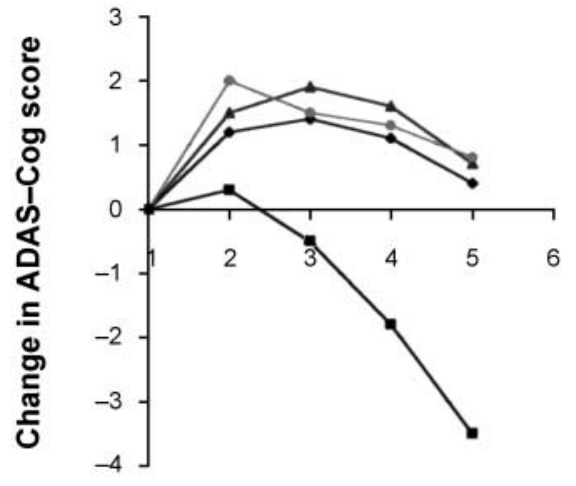

Visit number

Fig. I Combined clinical trial data for the three licensed acetylcholinesterase inhibitors: rivastigmine $(\diamond)$, donepezil $(\boldsymbol{\Delta})$ and galantamine $(\boldsymbol{O})$ versus placebo ( $\square$ ). The graph shows the change in cognition scores for patients assessed at 6-week intervals (positive change is improvement). ADASCog, Alzheimer's Disease Assessment Scale Cognitive section.

drug is chosen, the dose should be taken to the maximum tolerated (within the licence), after which at least 3 months of treatment should be given before considering whether there has been inadequate response. Rigidity may mean that late responders miss out on potential benefit - but within a limited budget, it will allow more patients exposure to treatment.

If one drug does not work or has intolerable side-effects, then another should be tried; although the three drugs belong to the same class, they are all different. There is no published information on switching the drugs. Convention when switching drugs is to leave an interval of five times the half-life of the first drug before commencing the second (that is, 60 hours for rivastigmine and 15 days for donepezil). Consensus suggests that 3 days should be left after treatment with rivastigmine or galantamine, while a week should be left following donepezil treatment. This is based on clinical practice - no controlled trial has been published.

\section{Which?}

The three drugs are similar yet have different individual characteristics (Table 1). How clinically relevant the differences are is unproven but interesting hypotheses are arising out of them.

\section{Donepezil}

Donepezil is very selective for acetylcholinesterase (AChE). This selectivity is claimed to reduce its side-effect profile, but published clinical data have not shown increased tolerability. Paradoxically, in Alzheimer's disease the level of AChE falls as the disease progresses (Arendt, 1992), matched by a rise in butyrylcholinesterase $(\mathrm{BuChE})$ - the function of which is unknown, but it forms part of the plaques and appears to come from the activated glial cells. What BuChE inhibition means is unclear, but rivastigmine and galantamine inhibit it, donepezil does not - they may work differently in later disease, although no published evidence has supported this.

\section{Rivastigmine}

Rivastigmine preferentially inhibits one of the four AChE subtypes - G1, found particularly in the hypothalamus and cortex. This subtype is implicated in plaque maturation, but whether there is any added clinical benefit to this specificity is again unproven.

\section{Galantamine}

Galantamine produces an effect on presynaptic nicotinic receptors called allosteric modulation (as does physostigmine and codeine). This produces increased amounts of acetylcholine in the synapse by a direct effect on presynaptic release, but again, the clinical impact is unknown and published evidence as to its significance and desirability is required. It may be that modulation, rather than agonism, protects against downregulation of post-synaptic receptors. This may allow the drug to work longer, but further studies are needed to confirm this. Modulation also improves attention, and this has been demonstrated with galantamine but not with donepezil or rivastigmine in Alzheimer's disease.

\section{When?}

The drugs are licensed for mild to moderate Alzheimer's disease. Patients with mild disease already have significant illness and should receive treatment, even with minimal symptoms. Treating mildly affected patients will mean smaller responses, and protocols should reflect this-long-term follow-up being needed to show any continuing effect beyond that expected from clinical trials. Moderate disease covers a wide range of morbidity: in trials down to a Mini-Mental State Examination (MMSE; Folstein et al, 1975) score of 10, but in NICE guidelines down to 12. Patients scoring at the lower end of the range have a host of symptoms, and AChEIs here may be as valuable for their symptomatic effects on behaviour as for their effect on the underlying disease. Trial data with metrifonate (another AChEI, which was withdrawn because of side-effects) showed improvement in neuropsychiatric symptoms in Alzheimer's disease - especially in apathy, hallucinations and agitation (Cummings et al, 1998). This effect is more noticeable in dementia with Lewy bodies where improvements in both MMSE scores and neuropsychiatric symptoms have been demonstrated with rivastigmine (McKeith et al, 2000). This suggests that dementia should be treated at any time, with symptomatic delay and retention of qualify of life being the aim early in the disease, moving towards symptomatic relief as progression occurs. No published results are available for severe dementia, though open-label follow-up from trials suggests that these drugs continue working as the cholinergic deficit increases.

\section{What?}

What about AChEIs in other dementias, plus other cholinergic therapies? Clinical trials are ongoing with AChEIs in vascular dementia and mixed dementia. No result is available as yet, but as the cholinergic system is implicated in these disorders it is hoped that findings will be positive. A study of rivastigmine in dementia with Lewy bodies has produced positive results (McKeith et al, 2000). Acetylcholinesterases are being studied as a potential treatment in mild cognitive impairment - a rational assumption as $55 \%$ of patients with this problem go on to develop Alzheimer's disease, and intervention here may have a profound effect on the burden of disease overall. No study of anticholinergic therapy in frontotemporal dementia is under way at present.

Muscarinic agonists have been tried in Alzheimer's disease, but these drugs have a narrow therapeutic window before sideeffects become intolerable, and to date no clinical trial has shown significant effects on cognition. Nicotinic drugs are also still in early trial stages, with similar tolerability problems to overcome, but more promising efficacy data. 


\begin{tabular}{|c|c|c|c|c|}
\hline & Donepezil & Rivastigmine & Galantamine & Clinical relevance \\
\hline $\begin{array}{l}\text { Efficacy - cognition and } \\
\text { global impression } \\
\text { (FDA guidelines) }\end{array}$ & Proved in pivotal clinical trials & Proved in pivotal clinical trials & Proved in pivotal clinical trials & All work in a similar way \\
\hline Safety & $\begin{array}{l}\text { No serious issues. Caution with } \\
\text { active peptic ulceration, } \\
\text { severe asthma and bradycardia } \\
\text { below } 50 \text { beats } / \mathrm{min}\end{array}$ & $\begin{array}{l}\text { No serious issues. Caution with } \\
\text { active peptic ulceration, severe } \\
\text { asthma and bradycardia below } \\
50 \text { beats/min }\end{array}$ & $\begin{array}{l}\text { No serious issues. Caution with } \\
\text { active peptic ulceration, severe } \\
\text { asthma and bradycardia below } \\
50 \text { beats } / \mathrm{min}\end{array}$ & $\begin{array}{l}\text { None has safety limitations - } \\
\text { good practice may suggest } \\
\text { patients should have ECGs }\end{array}$ \\
\hline Tolerability & $\begin{array}{l}\text { No serious issues. Insomnia, } \\
\text { agitation and leg cramps } \\
\text { reported }\end{array}$ & $\begin{array}{l}\text { No serious issues. Agitation } \\
\text { reported }\end{array}$ & $\begin{array}{l}\text { No serious issues. No clinical } \\
\text { reports as yet }\end{array}$ & $\begin{array}{l}\text { No difference in drop-out } \\
\text { rates in trials }\end{array}$ \\
\hline Side-effects & $\begin{array}{l}\text { Gastrointestinal; no real } \\
\text { difference from placebo } \\
\text { otherwise }\end{array}$ & $\begin{array}{l}\text { Gastrointestinal; no real } \\
\text { difference from placebo } \\
\text { otherwise }\end{array}$ & $\begin{array}{l}\text { Gastrointestinal; no real } \\
\text { difference from placebo } \\
\text { otherwise }\end{array}$ & $\begin{array}{l}\text { Gastrointestinal effects can be } \\
\text { limited by slow titration }\end{array}$ \\
\hline Dosing & Daily & Twice daily & Twice daily & Compliance issues \\
\hline Titration & $\begin{array}{l}\text { Two dosages: go from lower } \\
\text { to higher at } 4 \text { weeks }\end{array}$ & $\begin{array}{l}\text { Multiple dosage: slow titration } \\
\text { to maximum tolerated dose }\end{array}$ & $\begin{array}{l}\text { Three dosages: slow titration } \\
\text { to maximum tolerated dose }\end{array}$ & $\begin{array}{l}\text { Complex titration may } \\
\text { influence decisions in busy } \\
\text { services }\end{array}$ \\
\hline Pricing & Two-level & Flat rate & Three-level & Cost implications \\
\hline Inhibition & Reversible & Pseudo-irreversible & Reversible & Unknown \\
\hline Half-life & $72 \mathrm{~h}$ & $8 \mathrm{~h}$ & $7 \mathrm{~h}$ & $\begin{array}{l}\text { Easier to switch from drug } \\
\text { with shorter half-life }\end{array}$ \\
\hline Metabolism & Liver & By acetylcholinesterase itself & Liver & $\begin{array}{l}\text { Liver metabolism involves } \\
\text { P450 system - potential } \\
\text { interactions }\end{array}$ \\
\hline $\begin{array}{l}\text { Butyrylcholinesterase } \\
\text { inhibition }\end{array}$ & No & Yes (sponsor data) & No & Unknown \\
\hline Nicotinic modulation & No & No & Yes (sponsor data) & $\begin{array}{l}\text { Unknown, possibly improved } \\
\text { attention }\end{array}$ \\
\hline $\begin{array}{l}\text { Specific AChE subtype } \\
\text { inhibition }\end{array}$ & No & GI subtype & No & $\begin{array}{l}\text { Possible effect on plaque } \\
\text { maturation }\end{array}$ \\
\hline $\begin{array}{l}\text { Data in behavioural } \\
\text { symptom response }\end{array}$ & Yes & Yes & Yes - as part of pivotal trials & $\begin{array}{c}\text { Work in BPSD as well as } \\
\text { dementia treatment }\end{array}$ \\
\hline
\end{tabular}

AChE, acetylcholinesterase; BPSD, behavioural and psychological symptoms of dementia; ECG, electrocardiogram; FDA, Food and Drug Administration.

\section{NON-CHOLINERGIC DRUG THER APY}

Research into Alzheimer's disease has led to understanding of some of the pathological mechanisms involved. Inflammation occurs, as evidenced by the inflammatory markers found - for example, complement attack complex at levels similar to those found in ischaemic heart disease (McGeer \& McGeer, 1998). Basic science coupled with the observation that sufferers from rheumatoid arthritis have a lower rate of Alzheimer's disease (Stewart et al, 1997) has led to trials of anti-inflammatory drugs in the treatment of Alzheimer's disease. Trials with prednisolone have not been successful, but ongoing work with the cyclo-oxygenase inhibitors (especially Cox-2) in animal and now in human clinical trials may show benefit. These drugs are not without long-term sideeffects, so current practice is not to recommend their use routinely.

Another observational study has shown that women on hormone replacement therapy (HRT) have a reduced rate of Alzheimer's disease (Robinson et al, 1994). The protective effect of oestrogen on the nervous system and its vasculature is welldocumented (Birge, 1997), so clinical trials are now in progress to test the efficacy of oestrogen therapy (17 $\alpha$-oestradiol particularly). Early treatment study results are not encouraging (Mulnard et al, 2000), so again, in the absence of published positive studies, HRT cannot be recommended for use as a treatment in Alzheimer's disease - although it does seem that its use is increasing in Alzheimer's disease prophylaxis, particularly in the USA.

Antioxidants have shown benefit in several areas of chronic ill health, including Alzheimer's disease, after a study of selegiline and vitamin $\mathrm{E}$ and their effect on disease progression (Sano et al, 1997). This showed a positive effect on the rate of increasing dependency and delayed institutionalisation. However, this has yet to be replicated. Vitamin $\mathrm{E}$ is inexpensive and relatively safe - the trial was high dosage (2000 IU). Institutionalisation is expensive, so the return on this treatment is potentially high - but not rigorously 
proven. Many clinics are now routinely suggesting the use of vitamin $\mathrm{E}$ to patients with Alzheimer's disease - usually at about $1000 \mathrm{IU}$. It is possible that this may benefit other dementias and neurodegenerative disease as well.

Nootropic drugs are available for prescription in Germany - the best-known being Gingko biloba extract, nicergoline and piracetam. Precise modes of action are unclear, yet they do seem to produce an effect in some well-controlled studies.

Glutamate is increasingly implicated in dementia pathogenesis, with $N$-methyl-Daspartate (NMDA) blockade a putative therapy. Memantine, an NMDA blocker, has had positive results reported in severe Alzheimer's disease (e.g. Winblad \& Poritis, 1999), leading to application for regulatory approval for its use in dementia.

Nerve cell destruction seems secondary to activation of glial cells, so stabilisation of these glial cells may reduce the rate of Alzheimer's disease and other dementias. Several compounds such as propentofylline purportedly have this effect, especially in vitro, but to date have shown no therapeutic effect clinically. It remains a potential area of research.

The cortical cholinergic system is diffusely spread and a long way from its cell bodies. It is therefore dependent on nerve growth factor (NGF) to sustain it, and a reduction in NGF may be associated with Alzheimer's disease. Studies injecting NGF by cannulae into the cerebrospinal fluid showed some effect, but this is not a practical solution. Attempts to formulate the active portion of NGF into an oral preparation that crosses the blood-brain barrier are ongoing; meanwhile a xanthine derivative (leteprinim potassium) that seems to have a stimulating effect on NGF is about to start clinical trial.

\section{WHAT OF PLAQUES AND TANGLES?}

The pathological basis of Alzheimer's disease is the presence of amyloid plaques and neurofibrillary tangles. Most work has focused on the amyloid cascade that produces the plaques, and various drugs are in development to modify amyloid metabolism. The most imminent clinical trial is the injection of beta-amyloid protein to 'vaccinate' the individual and produce an antibody response that might remove amyloid from the nervous tissue. In mice this procedure relieved symptoms in genetic Alzheimer's disease animal models (Schenk et al, 1999) and prevented plaque formation in younger mice. This method is being tried in humans in both the UK and the USA, and represents the first true attempt at disease modification.

The other classical pathological change is the development of tangles, made up of abnormal tau protein. Tau pathology is known to exist in other neurodegenerative conditions and is an important area of research in treating other dementing diseases such as frontotemporal dementia and progressive supranuclear palsy. The hyperphosphorylation that occurs in Alzheimer's disease may be amenable to therapeutic intervention, and while there are some experimental models now to support this, no drugs are in clinical trials as yet.

\section{FUTURE CHALLENGES}

Basic science research is gradually unlocking some of the pathological sequences in dementia (especially in Alzheimer's disease) to provide theoretical treatment opportunities. This began with the AChEIs and is now at the stage of amyloid modification. For the first time therapeutic options exist in Alzheimer's disease and will soon be available in other dementias. These may be as simple as using vitamin $\mathrm{E}$, through to combinations of therapy to maximise benefit (Table 2). Although these treatments are still predominantly symptomatic, they offer relief to patients and have increased clinicians' awareness of the condition. This has taken old age psychiatry from its roots in social psychiatry to a point at which psychopharmacology has an important role. The challenge now is to learn how to use these treatments most effectively. This means that everyone in the speciality who uses these treatments has the opportunity to contribute to the debate, and the prospects of development over the next 10 years make this one of the most

Table 2 Current and potential treatments for dementia

\begin{tabular}{|c|c|c|c|}
\hline & Symptomatic & Disease modification & Cure \\
\hline \multirow[t]{4}{*}{ Probable - in use } & Acetylcholinesterase inhibitors: & Vitamin $\mathrm{E}$ & None \\
\hline & donepezil & ? AChEls & \\
\hline & rivastigmine & ? Memantine & \\
\hline & galantamine & ? Gingko biloba extract & \\
\hline \multirow[t]{6}{*}{ Possible - in clinical trial } & Muscarinic agonists & Antioxidants & None \\
\hline & Transmitter releasing factors/channel blockers & Oestrogen & \\
\hline & & NSAIDs & \\
\hline & & Nootropics, e.g. piracetam & \\
\hline & & NGF stimulators & \\
\hline & & Amyloid-modifying drugs and vaccines & \\
\hline \multirow[t]{4}{*}{ Possible - in clinical development } & Nicotinic agonists & Tau-modifying agents & ? Gene/gene product \\
\hline & & Amyloid-modifying agents & manipulation \\
\hline & & Gene product manipulation & \\
\hline & & Secretase blockers & \\
\hline
\end{tabular}

AChEls, acetylcholinesterase inhibitors; NGF, nerve growth factor; NSAIDs, non-steroidal anti-inflammatory drugs. 
exciting and dynamic areas of medicine in which to work.

\section{ACKNOWLEDGEMENTS}

The author thanks colleagues who have used these drugs to date for their participation in various consensus groups in order to fill in the gaps in this review where evidence remains weak.

\section{REFERENCES}

Arendt, T. (1992) Changes in acetylcholinesterase and butyrylcholinesterase in Alzheimer's disease resemble embryonic development; a study of molecular forms. Neurochemistry International, 21, 38I-396.

Birge, S. J. (1997) The role of oestrogen in the treatment of Alzheimer's disease. Neurology, $\mathbf{4 8}$ (suppl. 5), 36-40.

Bullock, R. (1998) Drug treatment for early Alzheimer's disease. Advances in Psychiatric Treatment, 4 $126-134$

\section{Cameron, I., Curran, S., Newton, P., et al (2000)} Use of donepezil for the treatment of mild-moderate Alzheimer's disease: an audit of the assessment and treatment of patients in routine clinical practice. International Journal of Geriatric Psychiatry, $\mathbf{1 5}$, 887-891.

Corey-Bloom, J., Anand, R., Veach, J., for the ENA 713 E352 study group (1998) A randomised trial evaluating the efficacy and safety of ENA 713 (rivastigmine tartrate), a new acetylcholinesterase inhibitor, in patients with mild to moderately severe Alzheimer's disease. International Journal of Geriatric Psychopharmacology, I, 55-65.

Cummings, J. L., Cyrus, P. A., Bieber, F., et al (1998) Metrifonate treatment of the cognitive deficits of Alzheimer's Disease. Metrifonate study group. Neurology, 50, $1214-1221$.

Davies, P. \& Maloney, A. J. F. (1976) Selective loss of central cholinergic neurones in Alzheimer's disease. Lancet, ii, 1403.

Evans, M., Ellis, A., Watson, D., et al (2000) Sustained cognitive improvement following treatment of Alzheimer's disease with donepezil. International Journal of Geriatric Psychiatry, I5, 50-53.

Folstein, M. F., Folstein, S. E. \& McHugh, P. R. (1975) 'Mini-Mental State': a practical method for grading the cognitive state of patients for the clinician. Journal of Psychiatric Research, 12, 189-198.

Harvey, R. J. (1999) A review and commentary on a sample of I5 UK guidelines for the drug treatment of Alzheimer's disease. International Journal of Geriatric Psychiatry, 14, 249-256.

Livingston, G. \& Katona, C. (2000) How useful are cholinesterase inhibitors in the treatment of Alzheimer's disease? A number needed to treat analysis. International Journal of Geriatric Psychiatry, 15, 203-207.

Matthews, H. P., Korbey, J., Wilkinson, D. G., et al (2000) Donepezil in Alzheimer's disease: eighteenmonth results from Southampton Memory Clinic. International Journal of Geriatric Psychiatry, I5, $713-720$

\section{CLINICAL IMPLICATIONS}

- Anticholinesterase therapy is a major contribution to the therapeutic treatment regimen in Alzheimer's disease - as now endorsed by the National Institute for Clinical Excellence.

- Psychopharmacology of Alzheimer's disease is now an important addition to the old age psychiatrist's skills - and professional development requirements.

- Services will need to move towards the diagnosis of early, mild dementia rather than intervene at the moderate to severe stages.

\section{LIMITATIONS}

- Funding of these new drugs may be hard to obtain, especially in areas where basic service needs are unmet and require attention first.

- These are only symptomatic treatments - we now need drugs that change the course of the illness.

- No single therapy is likely to be the solution to Alzheimer's disease. We need to learn how best to use cholinesterase inhibitors, and then how to combine them with new drugs as they arrive. It will be a while before this can be initiated at the level of primary care.

ROGER BULLOCK, MRCPsych, Department of Old Age Psychiatry and Kingshill Research Centre, Avon and Wiltshire Mental Health Trust, Victoria Hospital, Swindon SNI 4HZ, UK. Tel: +44 (0)। 793 43750I;

Fax: +44 (0)। 793 43752I ; e-mail: roger.bullock@kingshill-research.org

(First received 20 April 2000, final revision 29 May 2000, accepted 8 June 200I)

McGeer, P. L. \& McGeer, E. G. (1998) Mechanisms of cell death in Alzheimer's disease - immunopathology Journal of Neuronal Transmission, 54 (suppl.), $159-166$.

McKeith, I., Grace, J., Walker, Z., et al (2000) Rivastigmine in the treatment of dementia with Lewy bodies: preliminary findings from an open trial. International Journal of Geriatric Psychiatry, 15 387-392.

Mulnard, R. A., Cotman, C.W., Kawas, C., et al (2000) Estrogen replacement therapy for treatment of mild to moderate Alzheimer disease. JAMA, 283, 1007-1015.

National Institute for Clinical Excellence (200I) Guidance on the Use of Donepezil, Rivastigmine and Galantamine for the Treatment of Alzheimer's Disease. London: NICE.

Raskind, M. A., Peskind, E. R., Wessel, T., et al (2000) Galantamine in AD: a 6-month randomized placebo controlled trial with a 6 -month extension. Neurology, $\mathbf{5 4}$ $2261-2268$

Robinson, D., Friedman, L., Marcus, R., et al (1994) Estrogen replacement therapy and memory in older women. Journal of the American Geriatric Society, 42, 919-922.
Rogers, S. L., Farlow, M. R., Doody, R. S., et al (1998) A 24-week, double blind, placebo-controlled trial of donepezil in patients with Alzheimer's disease. Neurology, 50, $136-145$

Sano, M., Ernesto, C., Thomas, R. C., et al (1997) A controlled trial of selegiline, alpha tocopherol, or both, as treatment for Alzheimer's disease. New England Journal of Medicine, 336, 1216-1222.

Schenk, D., Barber, R., Dunn, W., et al (1999) Immunisation with $\boldsymbol{\beta}$-amyloid attenuates Alzheimer disease like pathology in the PDAPP mouse. Nature, 400, 173-177.

Schneider, L. S. \& Farlow, M. R. (1995) Predictin response to cholinesterase inhibitors in Alzheimer's disease: possible approaches. CNS Drugs, 4 , 114-124.

Stewart, W. F., Kawas, C., Corrada, M., et al (1997) Risk of Alzheimer's disease and duration of NSAID use. Neurology, 48, 626-632.

Winblad, B. \& Poritis, N. (1999) Memantine in severe dementia: results of the M-BEST Study (benefit and efficacy in severely demented patients during treatment with memantine). International Journal of Geriatric Psychiatry, 14, 135-146. 